\title{
How do consumers in developed countries value the environment and workers' social rights in developing countries?
}

\author{
Anne-Célia Disdier $\quad$ Stéphan Marette
}

\begin{abstract}
This paper uses a lab experiment to investigate developed countries' consumer valuations of the environment and workers' social rights in developing countries. It focuses on seafood products and distinguishes between regular, organic and fair trade varieties. Results show that environmental and social labels have similar effects on participant willingness-to-pay when they are first presented. Furthermore, the accumulation of labels does not influence the willingness-topay. Using welfare variation coming from the labels, we also show that the absence of negative information linked to the regular variety may lead to an underestimation of the value of information associated with the label.
\end{abstract}

Keywords: experimental economics, label, willingness-to-pay, value of information, seafood. JEL Classification: C9, D8, J8, Q5.

\footnotetext{
- INRA, UMR Economie Publique INRA-AgroParisTech, 16 rue Claude Bernard, 75231 Paris Cedex 05, France. Emails: anne-celia.disdier@agroparistech.fr, marette@agroparistech.fr

Acknowledgements: Financial support received by the "AgFoodTrade - New Issues in Agricultural, Food and Bioenergy Trade" (Grant Agreement no.212036) research project, funded by the European Commission, is gratefully acknowledged. The views expressed in this paper are the sole responsibility of the authors and do not necessarily reflect those of the Commission.
} 


\section{Introduction}

Environmentally-friendly and fair trade labeled products have emerged over the last two decades and their markets have expanded very rapidly. ${ }^{1}$ By enhancing production and export capacities, such products may contribute to the emergence of developing countries on the world market and to their economic growth. Some factors may however restrict their sales. At the macro-level, multilateral trade negotiations at the World Trade Organization (WTO), while acknowledging the important role played by such labels, do not make them mandatory. For instance, under WTO rules, countries cannot ban products based on the way they are produced (environment pollution, indecent working conditions, etc.). At the micro-level, consumers may not really trust such labels or are not willing to pay a premium for such products.

In this paper, we investigate developed countries' consumer valuations of the environment and workers' social rights in developing countries. Developed countries are indeed the main market for labeled products coming from developing countries. We use a lab experiment conducted in France in 2009 to evaluate the impact of information about environmental and social characteristics of products on consumer choice. We distinguish between regular and labeled varieties. Production of regular varieties may imply pollutions and/or may not respect decent social rights, while labeled varieties goods are made according to certain environmental and social production standards. Successive positive or negative information is delivered to participants. Our experiment focuses on shrimps. Several environmental and social issues affect their production in developing countries.

\footnotetext{
${ }^{1}$ According to Fairtrade Labelling Organizations International (2009), the retail value of fair trade products reached almost $€ 2.9$ billion in 2008 ( $+22 \%$ compared to 2007). Sales of organic food and drink reached $€ 33.7$ billion in 2007. About one-third of the world's organically managed land (almost 11 million hectares) is located in developing countries (Willer and Klicher, 2009).
} 
World shrimp production has grown rapidly during the last two decades. ${ }^{2}$ However, this boom has come at some cost. First, there are health costs as shrimps often contain bacteria (e.g. salmonella) or pesticide, drug and antibiotic residues. There are also concerns related to the environment with the destruction of mangroves and the depletion of rivers and groundwater sources for maintaining oxygen levels in farms (Greenpeace Canada, 2010). Other concerns deal with the illegal use of areas for shrimp aquaculture and corruption of local authorities, as well as bad working conditions. These costs are likely to play an increasing role in swaying both consumers' choices and international trade. Quality and organic labels have recently emerged for shrimps. However, they represent less than $1 \%$ of world production (Hervieu, 2009).

Results of the experiment show that information about environmental and social characteristics needs to be relatively precise in order to produce a significant impact on consumer willingness to pay (WTP). Second, environmental and social information has similar effects on consumer willingness-to-pay. Third, consumers are receptive to the first detailed characteristic stated in the experiment but do not react to the added characteristic presented in the second position. Consumers therefore seem to be insensitive to the accumulation of information or not ready to pay an additional premium for each product attribute, except when a negative message about food safety is presented at the end of the experiment. Lastly, based on the welfare variation, we show that the absence of negative information linked to the regular variety may lead to an underestimation of the value of information associated with the label. The cost of ignorance for consumers continuing to consume the regular variety when the labeled variety is introduced into the market should be taken into account for evaluating consumer surplus.

\footnotetext{
${ }^{2}$ In 1990, 2,636 tons of shrimps were produced in the world, while production reached 6,529 tons in 2007. About $80 \%$ of this production is concentrated in Asia. China, Thailand, Indonesia, India and Viet Nam are the top five world producers (Food and Agriculture Organization, 2009).
} 
This paper makes an important contribution to the experimental literature on labels. This literature shows that a significant proportion of consumers are willing to pay substantial premiums for environmentally friendly products (Blend and Van Ravenswaay, 1999; Nimon and Beghin, 1999; Wessells et al., 1999; Loureiro et al., 2001; Bougherara and Combris, 2009) or fair trade products (Arnot et al., 2006). However, there is still disagreement on whether or not labeling should combine different characteristics to increase WTP and to favor products from developing countries. Loureiro and Lotade (2005) compare WTP for coffee with fair trade or organic labels and Bernard and Bernard (2009) compare WTP for milk with conventional, organic, rBST-free or no-antibiotic characteristics. These papers offer a ranking of positive premiums for these new characteristics signaled by a label and suggest that consumers are very receptive to one characteristic. Our paper differs since we show that the ordering of information is crucial. Participants are receptive to the first-detailed characteristic presented in the experiment. However, we also highlight a fast-diminishing interest in the added characteristic presented in second position. This result suggests (i) the importance of the first/major information sent by advertising campaigns to consumers to signal new varieties, (ii) the difficulties of developing added attributes for new varieties when one attribute dominates a market and (iii) the possibilities of cumulating several labels to attract consumers with different priorities regarding the conditions of production and not consumers with utilities favoring added attributes.

The second contribution of our paper is to provide a complete estimation of the value of information associated with labels and defined by consumer surplus variations derived from the experimental results. This estimation includes all negative and positive information for a characteristic (social or environmental) that delineates the regular and the new labeled varieties. In the existing studies (Huffman et al., 2003 and 2007; Rousu et al., 2004 and 2007; Lusk et al., 2005; Rousu and Lusk, 2009 or Lusk and Marette, Forthcoming), all the 
information revealed in the experiment concerns only the newly introduced variety and not the regular/conventional variety. Our paper shows that the omission of the negative (or positive) information linked to the regular/conventional variety may bias the estimation of the information value. More precisely, this omission leads to an underestimation of the value of information associated with the label since the knowledge about the regular variety is still imperfect.

The next section describes the experiment. Results are reported in section 3. Section 4 provides econometric estimations of the determinants of consumer willingness-to-pay. Section 5 studies the value of information and consumer welfare. The paper concludes with a discussion of the implications of labels for the emergence of developing countries on the world market.

\section{Experiment}

This section details the sample, the product, the experimental procedure and the revealed information.

\subsection{Sample}

The sample consists of 160 people aged between 18 and 85 years. We conducted the experiment in Paris, France, in multiple one-hour sessions in December 2009. The sample of participants was randomly selected based on the quota method. Participants were contacted by phone. They were informed that the experiment would focus on food behavior and shrimp consumption and would last about one hour with a 15-euro participation fee. The sample is relatively representative of the age-groups and the socio-economic status of the population of the city although retired people are slightly over-represented. 
In our experiment, the sample is divided into four groups (see the explanation and the table 2 below). Participants are randomly assigned to one group. Table 1 presents the socioeconomic characteristics (gender, age, education, income, household composition) of participants within each group. Differences between groups are tested using the Pearson chisquare test. A $P$ value (against the null hypothesis of no differences) less than $5 \%$ is considered significant. Results suggest that the four groups are not significantly different except for gender at the 5\% level. In this latter case, group IA is slightly different from the three others. Once this group is excluded, the test is no longer significant.

Insert table 1 here

\subsection{Product}

The experiment focuses on a 100g plastic package of farmed, midsize, shelled, cooked and refrigerated shrimps. Cooked and refrigerated shrimps are the most consumed shrimps in France (two-thirds of all consumption of shrimps both in value and quantity in 2008 according to the FranceAgriMer, 2008). ${ }^{3}$ As no major brand dominates the market, the private brand (linked to a French supermarket) is concealed to avoid any influence of this supermarket brand. For fair trade and organic shrimps, the picture of the product is accompanied by a fair trade or organic label.

The experiment elicits hypothetical responses, since we do not offer the real product at the end of the experiment, and this for three reasons. First, as no fair trade shrimps are sold in France, it is not possible to give a real "fair trade" variety of the product to participants at the end of each lab session if their choices lead them to favor this variety during the experiment. Second, there is no brand offering both conventional and organic varieties,

\footnotetext{
${ }^{3}$ Statistics do not distinguish between shelled and non-shelled shrimps.
} 
making the auctions and the isolation of the premium linked to the organic characteristic very complex. Third, the cold process linked to refrigeration makes the sale/distribution of real products to participants hazardous in terms of food safety. However, despite possible hypothetical biases in the WTP elicitations, the protocol precisely controls the revelation of information in the lab.

\subsection{Experimental design and revealed information}

The experiment is divided into several stages as described in figure 1. Participants receive general instructions and sign a consent form. They fill in an entry questionnaire on consumption behavior and socio-demographic characteristics. Five successive types of information are then communicated. After each round of information revelation, participants fill in a multi-price list (or payment card) presented on a paper sheet, which allows elicitation of the WTP. Participants fill in an exit questionnaire and receive the $€ 15$ indemnity.

\section{Insert figure 1 here}

While the complete information revealed to participants is given in appendix 1, it is possible to sum up the content delivered at different points in the experiment as follows:

First, we provide general information about the shrimps preceding the participants' choice \#1 to elicit WTP. A price range of existing prices observed in supermarkets (between $€ 1.50$ and $€ 4$ for $100 \mathrm{~g}$ of farmed, midsize, shelled, cooked and refrigerated shrimps enclosed in a plastic package) is mentioned.

Second, we provide brief information on concerns about the environment and working conditions preceding the participants' choice \#2. 
- $\quad$ Third, before choices \#3, \#4 and \#5 we provide successive additional information about possible environmental and working conditions and safety attributes linked to shrimps. The environmental and social information precedes the information about safety, which is always revealed at the end of the experiment (before choice \#5). Previous experiments reveal that safety information is a priority for participants eclipsing other characteristics (see Marette et al., 2009), while in this experiment we want to ignore food safety considerations except at the end of the experiment.

We conduct the experiment in four treatments, varying the type (positive vs. negative) and the order of information about green and ethical characteristics (respectively before choices \#3 and \#4). Table 2 describes the experimental design and the corresponding number of attendants.

\section{Insert table 2 here}

A multiple price list is used for eliciting WTP for 100g of farmed, cooked, midsize, shelled and refrigerated shrimps sold in a plastic package. During each choice phase, participants are asked to choose whether or not they will buy the product for prices varying from $€ 0.25$ to $€ 4$ with a 25 -cent interval between possible choices. A colored picture of the shrimp package is posted on the paper sheet. For fair trade and organic shrimps, we also post a "fair trade" or "organic" label. For each price, participants have to check off either "yes", "no" or "maybe" regarding their purchase intentions. The option "maybe" is useful for

capturing hesitation that differs from a firm "yes". For each choice $\# i$ with $i=1, \ldots, 5$, the WTP is determined by taking the highest price linked to a "yes" choice (with the following highest price on the paper sheet implying a reply "no" or "maybe" capturing hesitation). If during a choice \#i, no "yes" is checked off, we set the WTP to zero (recall that the first choice was for 
a price equal to $€ 0.25$ ). If during a choice $\# i$, "yes" is always selected, we arbitrarily set the WTP to $€ 4$.

Andersen et al. (2006) underline two disadvantages of the multiple price list. The first disadvantage is the interval response eliciting interval from participants rather than point estimates for WTP. With our experiment, the 25-cent interval guarantees enough precision for the elicited WTP. The other disadvantage is the framing effect with a psychological bias towards the middle of the multiple price list for choices made by participants. Andersen et al. (2006) control for this effect by changing the boundaries of the multiple price list. In this paper we do not control for this framing effect, since we focus on the impact of the revelation of information and messages. The psychological bias is plausible for the first round of our experiment, $18.1 \%$ of participants expressing a WTP of $€ 2$. However, this effect disappears after the revelation of information. Only $11.3 \%$ of participants make a bid of $€ 2$ in choice \#2, and this percentage becomes less than $6 \%$ in choices \#3, \#4 and \#5.

Despite these limitations, the multiple price list methodology is useful for providing information regarding the consumers' WTP. The main advantage is the simplicity of the explanation given to participants at the beginning of the experiment, which differs from auction mechanisms where organizers need to convince participants that bid manipulation is useless under a Vickrey mechanism. We now turn to the results.

\section{Experimental results}

Figures 2 and 3 show the average WTP in euro for $100 \mathrm{~g}$ of shrimps. This average takes into account bids by all participants, including the ones with WTP equal to zero because of no "yes" checked off. The standard deviation is reported in parentheses. Recall that groups IA and IB presented in figure 2 (respectively groups IIA and IIB presented in figure 3) receive 
positive information with labels (respectively negative information). The $x$-axis of each figure details under each bar the round of choice $i$ with $i=1, \ldots, 5$ and the information preceding the choice leading to the WTP elicitation. The indicators $\Delta$ isolate the significant impact of a single round of additional information. We test for the significance of the WTP differences following a single round of information (namely, between WTP \#i and WTP \#i+1) by using the Wilcoxon test for paired samples and indicate the significant differences at the $1 \%, 5 \%$, and $10 \%$ level.

\section{Insert figures 2 and 3 here}

Seven main results could be highlighted:

(i) The initial WTP before the revelation of any information about social, environmental and health-related conditions is similar across groups and close to observed data in France. A Kruskal-Wallis test concludes that the valuation for the first round across the four groups is not statistically significant. This first choice is also interesting for comparing the percentage of participants purchasing the product for a given price with observed data in France. A participant is assumed to purchase the product if its WTP is equal to or higher than the price observed on average in French supermarkets. The observed average price is equal to $€ 2.2$. With such a price, $50 \%$ of participants across the 4 groups would purchase the shrimps, which is close to the $48.9 \%$ of French consumers buying shrimps in 2008 (see p.34 in FranceAgriMer, 2008). This result suggests that the hypothetical bias is limited.

(ii) A short and vague message does not influence consumers with pre-existing knowledge about the question studied in the experiment. The revelation of short and general information about environment and social conditions before choice $\# 2$ does not lead to a significant change in WTP for groups IA, IB and IIB. For group IIA, the Wilcoxon test for paired samples shows that the difference in WTP between the first and the second bars is 
significant but only at the $10 \%$ level. Interestingly, the group IIA is the one with the lowest pre-existing knowledge in our sample (see table 1). This result differs from conclusions showing that short and simple information is efficient for changing WTP (see Wansink et al., 2004). Clearly, there are no definitive conclusions that depend on both the products and the characteristics at stake.

(iii) A sufficient level of precision in the revealed information is efficient for changing WTP. Participants react to the second and more precise round of information (before choice \#3). The differences in WTP between the second and third bars of each graph are significant, except for group IIB (significant at $10.1 \%$ only).

(iv) Positive information has a larger impact in absolute value than negative information. The average variation in absolute value between the second and third bars is equal to $€ 0.73$ for group IA, $€ 0.75$ for group IB and only to $€ 0.48$ for group IIA, $€ 0.34$ for group IIB. This diverges from some results on food safety showing that negative information has a larger impact than positive information (see Hayes et al., 1995; Fox et al., 2002).

(v) Different labels have similar effect. The average WTP expressed by group IA for the fair trade label is very close to the average WTP expressed by group IB for the organic label (third bars of figure 2). The Mann-Whitney-U test across these 2 groups reveals that valuations for the third rounds are not statistically different, even if labels are different. Interestingly, the same result occurs when one focuses on negative information. According to the Mann-Whitney-U test, valuations for the third rounds are not statistically different across groups IIA and IIB.

(vi) Consumers' WTP does not seem to be influenced by the accumulation of labels or negative information. The additional information about the second characteristic (before choice \#4 leading to the $4^{\text {th }}$ bar) does not impact WTP for the four groups of participants. This is true whatever the type of information (positive vs. negative) and in case of positive 
information whatever the type of labels (organic or fair trade). Similarly, the last information about safety (before choice $\# 5$ leading to the $5^{\text {th }}$ bar) clearly matters for groups IA and IB, which previously received only positive information. The effect is much smaller and significant only at the $10 \%$ level for group IIA and even not significant for group IIB.

(vii) Experiment results are driven by neither an information effect per se nor a tiredness effect. First, the revelation of short and general information before choice \#2 does not lead to a significant change in WTP for groups IA, IB and IIB, suggesting the absence of an information perturbation whatever its content (information effect per se). As a consequence, the significant impact of information before choice \#3 can really be interpreted as a shock coming from the content of positive information (groups IA and IB) or negative information (groups IIA and IIB). Second, the significant impact of the last round of information before choice \#5 indicates that participants' attention does not suffer from a tiredness effect. The non-significant impact of information before choice \#4 can therefore be interpreted as the absence of an additional premium for a second characteristic (under both positive and negative information).

Before turning to the econometric estimations, we provide some details on participants' perceptions of the environment, social rights in developing countries and food safety. Questions on these issues were asked to participants in the entry and exit questionnaires. Participants rated their perceptions on an increasing scale ranging from 1 to 10. Table 3 reports mean perceptions and standard deviations for each group. Kruskal-Wallis tests show that the valuations for each question across the four groups are not statistically different. Results suggest that participants attach high importance to the protection of the environment and workers' rights. However, they do not feel very well informed about safety and environmental problems. Furthermore, they do not have a high degree of trust in organic and fair trade labels. Interestingly, groups IIA and IIB, which receive negative information, 
trust labels less than groups IA and IB, which receive positive information. Questions on trust in labels were asked after the revelation of messages on shrimps and WTP elicitation; it is likely that such messages influenced answers to further questions on trust. Some of these participants' perceptions will be used in the econometric estimations as control variables (see table 4). We turn to the econometric estimations.

\section{Insert table 3 here}

\section{Econometric estimations}

We now provide more explanations regarding the results of figures 2 and 3 and investigate the determinants of WTP. To do so, we regress WTP expressed by participants at each round $i$ (with $i=1, \ldots, 5)$ on information and participants' characteristics. Results are presented in table 4. Columns (1) to (6) perform OLS regressions, while column (7) reports the result of a Tobit estimation.

We first examine whether the revelation of positive information (respectively negative) increases (respectively decreases) participants' WTP (column (1)). Two dummies, one for each type of information, are defined: 'positive information' is set to one for choices \#3 and \#4 for groups IA and IB and 0 otherwise (see table 2). 'Negative information' equals 1 for choices \#3 and \#4 for groups IIA and IIB and for choice \#5 for all groups (see table 2 and appendix 1; revealed information before choice \#5 deals with safety risk). Since the short and vague message before choice \#2 does not lead to a significant change in WTP for 3 groups (see figures 2 and 3), we do not consider it when defining the dummies. Estimated coefficients on both dummy variables have the expected sign and are significant at the $1 \%$ level: revealed positive information increases participants' WTP, while negative information decreases it.

Column (2) controls for the socio-economic characteristics of participants: sex, age, 
presence of children in the household, and level of education. Some answers are missing and consequently 15 observations are dropped. However, it does not affect the results. ${ }^{4}$ Except for age, all socio-economic variables are dummy variables. For education, we define three levels: low (below the baccalaureate - BAC -, which is the French high school diploma), medium (between $\mathrm{BAC}$ and $\mathrm{BAC}+2)$ and high $(\mathrm{BAC}+5$ and more). Due to multicollinearity, the first level is used as the reference level and the estimated coefficients on the two other levels should be compared to it. Results suggest that sex has no influence on WTP. All other socioeconomic variables are significant at the 5\% level. All other things being equal, younger people express a smaller WTP, while people with at least one child and a medium or high level of education state a higher WTP. The F-test shows that estimated coefficients on education variables are not significantly different. The introduction of socio-economic controls does not significantly change the estimated coefficients on the information variables.

Instead of socio-economic characteristics, column (3) controls for participants' perceptions of the environment and workers rights in developing countries. We focus on the importance attached by participants to these issues. As shown in table 3, participants value such issues highly. Ratings expressed by participants on an increasing scale ranging from 0 to 10 are converted into dummies. These dummies are set to 1 for ratings above 5 and to 0 otherwise. Results suggest that the importance attached by participants to the protection of workers' rights in developing countries does not influence WTP. Quite surprisingly, the importance attached to the protection of the environment has a negative and significant $(p<0.05)$ impact on WTP. As in column (2), estimated coefficients on the information variables are very stable.

Column (4) includes both socio-economic and perception controls. The magnitude and level of significance of parameters remain unchanged. The $\mathrm{R}^{2}$ is equal to 0.198 , which is

\footnotetext{
${ }^{4}$ The exclusion of these 15 observations from the regression presented in column (1) does not significantly
} 
similar to what is usually found in the literature.

In column (5), the sample is restricted to the first four choices. The last choice, after the revelation of the negative information on food safety, is excluded from the estimation. The coefficient on the 'negative information' variable is reduced compared to the previous estimations. This result is not really surprising since safety risks tend to negatively influence participants' WTP (see figures 2 and 3). Interestingly, the coefficients on information dummies (in absolute terms) are now almost similar (0.75 vs. 0.73). Estimated coefficients on education variables become insignificant. However, except for this change, all other previous conclusions on socio-economic and perception controls still hold.

In column (6), we interact the dummies on positive and negative information with dummies on the type of revealed information: environmental, social or health-related. According to table 2, the dummy for 'social information' is set to one for choice \#3 for groups IA and IIA and choice \#4 for groups IB and IIB ( 0 otherwise). The dummy for 'environmental information' is set to one choice \#3 for groups IB and IIB and for choice \#4 for groups IA and IIA (0 otherwise). Lastly, the dummy for 'safety information' is set to one for choice \#5 for all groups ( 0 otherwise). The interaction terms are all significant at the $1 \%$ level and have the expected sign: positive social and environmental information increases WTP, while negative environmental, social and safety information reduces WTP. Interestingly, the F-tests show that the interaction terms (positive $\mathrm{x}$ social and positive $\mathrm{x}$ environmental information on one hand and negative $\mathrm{x}$ social, negative $\mathrm{x}$ environmental, and negative $\mathrm{x}$ safety information on the other hand) are not significantly different. Socioeconomic and perception controls are not influenced by the inclusion of the interaction terms.

Finally, column (7) presents the results of the Tobit estimation. In our sample, WTP range from 0 to 4 and are therefore left- and right-censored. Our sample includes 232 left-

affect the results. 
censored observations $(\mathrm{WTP}=0), 74$ right-censored observations $(\mathrm{WTP}=4)$, and 494 uncensored observations $(0<\mathrm{WTP}<4)$. Tobit estimated coefficients are slightly higher than those reported column (6). However, previous conclusions remain unchanged. Furthermore, the F-tests again suggest the absence of significant differences between the interactions terms. We now turn to the surplus estimation based on the WTP elicited in the experiment.

\section{Insert table 4 here}

\section{Value of information and consumer welfare}

The WTP can be used to determine the consumer surplus and the value of information. Following Foster and Just (1989) and Teisl et al. (2001), information is welfare enhancing if consumers change their consumption behavior. The contribution of our experiment is twofold. First, we investigate whether positive and negative information for the same characteristics has a similar impact on participants' behaviors. Second, we combine both positive and negative information to estimate consumer welfare. Our approach therefore differs from the previous studies focusing only on the effect or/and the value of information related to the labeled variety (Huffman et al., 2003 and 2007; Rousu et al., 2004 and 2007; Lusk et al., 2005; Rousu and Lusk, 2009).

We focus on the information delivered just before choice \#3. This information significantly impacts WTP for three of the four groups, namely groups IA, IB and IIA (see figures 2 and 3), ${ }^{5}$ and therefore its welfare impact can be computed by comparing $W_{T} P_{3}$ and $W T P_{1}$. The focus on this third message presents three main advantages:

(i) When positive information linked to a label is revealed to groups IA and IB, consumers are aware of a new purchasing option. In this case, we may simulate the 
introduction of a new variety of the product signaled by a label, namely the fair trade label for group IA and the organic label for group IB.

(ii) When negative information about the regular/conventional variety is revealed to groups IIA and IIB, consumers may take different action compared to the absence of precise information. In this case, we may determine a cost of ignorance. The negative information may characterize media coverage or a campaign by a non-governmental organization.

(iii) Eventually, we combine both types of positive and negative information in a way described below, to have a complete view when different varieties of a given product coexist on the market. This approach is overlooked in previous studies where all the positive or negative information revealed in the experiment only concerned the GM variety and not the regular (or conventional) variety.

\subsection{Positive information about the new (labeled) variety}

With the positive information linked to a labeled variety for groups IA and IB, we can measure the impact of a label introduction on participants' surplus. Before measuring the value of information, we determine the participants' purchase choices in periods 1 and 3 . We assume that a participant purchases a good if their WTP for the good is higher than the price observed on average in the supermarkets in France. Before choice \#1, only "regular" shrimps are offered, and the participant can choose between two outcomes: regular at price $P_{R}$ and none. The participant $j$ chooses the option generating the highest utility, namely:

$$
C S_{1}^{j}=\max \left\{W T P_{1}^{j}-P_{R}, 0\right\}
$$

\footnotetext{
${ }^{5}$ For group IIB, the information is significant at $10.1 \%$ only when we compare $\mathrm{WTP}_{2}$ and $\mathrm{WTP}_{3}$ (see figure 3 ). However, the comparison of $\mathrm{WTP}_{1}$ and $\mathrm{WTP}_{3}$ for this group IIB shows a statistically significant difference at $1 \%$.
} 
where the subscript 1 denotes the bid linked to choice \#1 for a participant $j$ (with $j=1, \ldots, N$ ).

When a label is introduced at price $P_{L}$ (before choice \#3), the participant can choose between three outcomes: regular variety, labeled variety, and none. She/he chooses the alternative, which generates the highest utility, and thus:

$$
C S_{3}^{j}=\max \left\{W T P_{1}^{j}-P_{R}, W T P_{3}^{j}-P_{L}, 0\right\}
$$

We now turn to the value of information by using two metrics to compute the average value for each group IA or IB receiving positive information. The participant surplus change from a label introduction, if all participants are fully informed about the label, is:

$$
\Delta C S_{\text {Label }}^{K}=\frac{\sum_{j=1}^{K}\left[C S_{3}{ }^{j}-C S_{1}{ }^{j}\right]}{K}=\frac{\sum_{j=1}^{K}\left[\max \left\{W T P_{1}^{j}-P_{R}, W T P_{3}^{j}-P_{L}, 0\right\}-\max \left\{W T P_{1}^{j}-P_{R}, 0\right\}\right]}{K} .
$$

where $K$ can take two values. First $K=S_{P}$, where $S_{P}$ is the number of switchers receiving positive information who start to consume the labeled variety after its introduction. In this case, the information revelation only modifies the surplus of these switchers. Conversely, the surplus variation is zero for participants who do not change their behavior, namely by continuing to choose the regular variety or nothing when the label is introduced and when $P_{R}$ is constant (which is the case under constant-return to scale for producers). Second, $K=N_{P}$, where $N_{P}$ is the overall number of participants within a group receiving positive information. The measure given by (3) is similar to the one provided in papers focusing on the introduction of GMOs (see the introduction for the references).

\subsection{Negative information about the regular variety}

With the negative information revealed to groups IIA and IIB, we can measure the cost of ignorance linked to the lack of precise information (as before choice \#1). When the negative and precise information (before choice \#3) is revealed to groups IIA and IIB, some participants stop buying the product. For a participant $j$, the cost of ignorance linked to the 
absence of complete information about a characteristic before choice $\# 1$ is $C O I^{j}=I_{j}\left[W T P_{1}^{j}-W T P_{3}^{j}\right]$ where $I_{j}$ is an indicator variable taking the value of 1 if participant $j$ is predicted to have chosen the regular variety at price $P_{R}$ with $W T P_{1}^{j}>P_{R}$ in choice $\# 1{ }^{6}$ The cost of ignorance reduces the participant's surplus associated with choice \#1. By taking into account $C S_{1}^{j}=\max \left\{W T P_{1}^{j}-P_{R}, 0\right\}$ (see equation 1), the overall surplus is:

$$
C S C_{1}^{j}=C S_{1}^{j}-C O I^{j}=\max \left\{W T P_{1}^{j}-P_{R}, 0\right\}-I_{j}\left[W T P_{1}^{j}-W T P_{3}^{j}\right]
$$

When negative information is revealed, outcomes remain unchanged (regular varieties or none). However, participants may adjust their consumption, and the surplus becomes $\overline{C S}_{3}^{j}=\max \left\{W T P_{3}^{j}-P_{R}, 0\right\}$. For each group IIA or IIB, the value of information or total surplus change for participants linked to the revealed information is given by:

$$
\begin{aligned}
\Delta C S_{\text {Neg }}^{K} & =\frac{\sum_{j=1}^{K}\left[\overline{C S}_{3}^{j}-C S C_{1}^{j}\right]}{K} \\
= & \frac{\sum_{j=1}^{K}\left[\max \left\{W T P_{3}^{j}-P_{R}, 0\right\}-\left(\max \left\{W T P_{1}^{j}-P_{R}, 0\right\}-I_{j}\left[W T P_{1}^{j}-W T P_{3}^{j}\right]\right)\right]}{K}
\end{aligned}
$$

where $K=S_{N}$ (the number of switchers) or $K=N_{N}$ (the overall number of participants within a group receiving negative information). In this context, $S_{N}$ is the number of switchers that stop consuming the product when the negative information is revealed before choice \#3.

\subsection{Combination of the positive and negative information}

Eventually, one can combine the negative and positive information across the groups. The value of information is computed to measure the impact of a fair trade or organic label by including the average value of the cost of ignorance linked to the revealed negative

\footnotetext{
${ }^{6}$ Since we focus on the cost of ignorance linked to the characteristic revealed in stage \#3, the computed cost of ignorance is partially incomplete because it ignores the negative information revealed at stage \#4 and the safety information revealed at stage $\# 5$.
} 
information. The existence of a new label may lead many consumers to question the existence of "bad" characteristics linked to regular varieties.

For the groups IIA and IIB receiving negative information, the average value of the cost of ignorance linked to regular varieties is:

$$
E(C O I)=\frac{\sum_{j=1}^{N_{N}} I_{j}\left[W T P_{1}^{j}-W T P_{3}^{j}\right]}{\sum_{j}^{N_{N}} I_{j}}
$$

where $\sum_{j=1}^{N_{N}} I_{j}$ is the number of participants who purchase the good based on WTP revealed by choice \#1.

The average measure $E(C O I)$ coming from group IIA is integrated in the participant's $j$ surplus for group IA receiving positive information (the equivalent can be made for groups IIB and IB). By taking into account $C S_{1}^{j}=\max \left\{W T P_{1}^{j}-P_{R}, 0\right\}$ given by (1) and linked to the choice \#1, the overall surplus with only regular varieties on the market is:

$$
C S D_{1}^{j}=C S_{1}^{j}-E(C O I)=\max \left\{W T P_{1}^{j}-P_{R}, 0\right\}-I_{j} E(C O I)
$$

The introduction of the label leads to two situations, namely case 1 and case 2 . Under case 1, participants faced with a label are only aware of the positive information coming from the label for choosing between options (regular, label, and none), but their choices may be distorted because of a lack of information regarding the regular variety. Their surplus is $C S D_{3}^{j}=\max \left\{W T P_{1}^{j}-P_{R}, W T P_{3}^{j}-P_{L}, 0\right\}-I I_{j}{ }^{R} E(C O I)$, where $I I_{j}^{R}$ is an indicator variable taking the value of 1 if participant $j$ is predicted to have chosen the regular variety at price $P_{R}$ when the label exists on the market. In this case, the value of information is: 


$$
\begin{gathered}
\Delta C S D_{\text {Label }}^{K}=\frac{\sum_{j=1}^{K}\left[C S D_{3}{ }^{j}-C S D_{1}{ }^{j}\right]}{K}= \\
\frac{\sum_{j=1}^{K}\left[\max \left\{W T P_{1}^{j}-P_{R}, W T P_{3}{ }^{j}-P_{L}, 0\right\}-I I_{j}{ }^{R} E(C O I)-\left(\max \left\{W T P_{1}^{j}-P_{R}, 0\right\}-I_{j} E(C O I)\right)\right]}{K}
\end{gathered}
$$

where $K=S_{P}$ (the number of switchers) or $K=N_{P}$ (the overall number of participants within a group receiving positive information).

Under case 2, participants faced with a label are fully aware of both the positive information coming from the label and the negative aspects linked to regular varieties when they choose between regular, label or none. The emergence of a label may indeed lead to awareness of negative aspects linked to the regular varieties. For instance, participants realize to what extent regular varieties are bad or dangerous. Thus, their surplus is $C S E_{3}^{j}=\max \left\{W T P_{1}^{j}-E(C O I)-P_{R}, W T P_{3}^{j}-P_{L}, 0\right\}$. Their WTP for the regular variety at price $P_{R}$ is $W T P_{1}^{j}-E(C O I)$ if they are aware of the negative aspect based on the average cost of ignorance $E(C O I)$ that is internalized in their demand. In this case, the value of information is:

$$
\begin{aligned}
& \Delta C S E_{\text {Label }}^{K}=\frac{\sum_{j=1}^{K}\left[C S E_{3}{ }^{j}-C S D_{1}^{j}\right]}{K} \\
& =\frac{\sum_{j=1}^{K}\left[\max \left\{W T P_{1}^{j}-E(C O I)-P_{R}, W T P_{3}^{j}-P_{L}, 0\right\}-\left(\max \left\{W T P_{1}^{j}-P_{R}, 0\right\}-I_{j} E(C O I)\right)\right]}{K}
\end{aligned}
$$

where $K=S_{P}$ (the number of switchers) or $K=N_{P}$ (the overall number of participants within a group).

All these measures indicating the value of information (or the welfare variation linked to more complete information) lead to the following results presented in table 5. Based on 
observations across several supermarkets, we use $P_{R}=€ 2.2$ and a price premium equal to $25 \%$ for the varieties with a label leading to $P_{L}=€ 2.75$ (see Hervieu, 2009). ${ }^{7}$

The first three lines of table 5 measure the value of information as in previous papers by focusing on the information related to the new variety. Lines 4-6 measure the value of negative information linked to the regular variety. The value of the negative information is higher than the value of the positive information, because of a higher number of switchers stopping consumption of the regular variety when negative information is revealed. This result shows the importance of taking into account the cost of ignorance coming from the regular variety when measuring the value of information.

Results based on the combination of positive and negative information are presented in the bottom part of table 5. Both cases 1 and 2 show a relative large value of information, which is higher than that observed when only the information related to the new variety is accounted for. Thus, by focusing only on the information related to the new variety, previous welfare measures underestimate the value of information. Robust evaluations need to combine both negative and positive information. Interestingly, our results also show that the two average values of information over all participants given in the last line of table 5 are relatively high compared to a price $P_{R}=€ 2.2$ considered for the estimations of the surplus variation coming from the information. This suggests a high-social benefit linked to the complete revelation of information to consumers. This benefit should be compared to regulatory costs coming from quality monitoring and advertising efforts.

\section{Insert table 5 here}

Moreover, fully revealing negative and positive information generates higher WTP by developed countries' consumers that can be of benefit to producers from developing

\footnotetext{
${ }^{7}$ Hervieu (2009) emphasizes that organic shrimp production requires $25 \%$ more work than regular shrimps, which leads us to assume a price increase equal to $25 \%$. Since fair trade shrimps are not available in France, we assume that the price premium for such shrimps is similar to the one observed for organic shrimps.
} 
countries. The results of the experiment could therefore be used to measure the increase in producers' marginal income from a complete development of labels, where both labeled and regular varieties would be offered everywhere in France. The simulation is as follows: In France, the consumption of farmed tropical shrimps is $56,548,800 \mathrm{~kg}$ per year. ${ }^{8}$ To carry out the income estimation, we consider the participants who switch to labeled varieties after the information revelation. Among them, we distinguish the percentage $x$ of participants who purchase regular variety before the label introduction and the percentage $y$ of participants who do not purchase shrimps before the label introduction. The income increase for producers comes from these consumers changing varieties at a better price $P_{L}$ compared to $P_{R}$ and from the new consumers purchasing goods at price $P_{L}$. Ignoring any cost consideration the increase in producers' marginal income is defined by $56,548,800^{*}\left[x^{*}\left(P_{L}-P_{R}\right)+y^{*} P_{L}\right]$ and presented in table 6 . Although these estimations are imperfect because of the absence of precise information, they show significant increase in producers' income that may cover additional label-sunk costs (not passed into the price $P_{L}$ ) and generate higher income compared to the existing situation.

\section{Insert table 6 here}

In order to keep the mathematical aspects as simple as possible, the estimation of the welfare variations based on equations (1) to (9) was admittedly simple. In order to fit different problems from various contexts, some extensions could be integrated into the model presented here. First, the prices of varieties $P_{R}$ and $P_{L}$ were assumed constant for the sake of simplicity, while an extension with an increasing supply function under decreasing returns to scale would lead to a price increase of organic and fair trade varieties and a price decrease of

\footnotetext{
${ }^{8}$ This volume is calculated by taking the total consumption of shrimps in France in 2008 and multiplying it by the percentage of shrimps that are tropical $(80 \%)$ and by the percentage of farmed shrimps $(60 \%)$. Statistics sources: FranceAgriMer (2008) and Food and Agriculture Organization (2009).
} 
regular varieties when complete information is revealed. ${ }^{9}$ Second, if the positive information can be provided by a label voluntarily chosen by producers, the negative information related to the regular variety is more difficult to reveal. However, a per-unit Pigouvian tax equal to $E(C O I)$ imposed on the regular variety could favor clean or fair varieties and generate better income for producers from developing countries searching for added-value products.

\section{Conclusion}

These results suggest that environmental and social information has similar effects on participant willingness-to-pay when it is first presented. Furthermore, the accumulation of labels seems useless, which means that farmers from developing countries should carefully consider the type of labels they should use to improve quality and capture consumer WTP. Developing organic varieties could be a "bonanza" for shrimp producers as the organic logo is already known by consumers in developed countries.

Using welfare variation from the organic or fair trade labels, we also show that the absence of negative information linked to the regular variety may lead to an underestimation of the value of information associated with the label. The consumers' choices are distorted since the negative information linked to the regular variety is not internalized by consumers. The segment for products with labels could be expanded. This last result underlines that the benefit of complete information could be high not only for French consumers but also for shrimp producers developing high-quality products.

Improving the quality of agricultural products is one way to increase income in developing countries, even if choosing the type of labels or the advertising strategy is challenging for these producers. An experiment in some shrimp farms in Asian countries to

\footnotetext{
${ }^{9}$ In table 5, we ignored welfare variation from equilibrium-price variation under decreasing return to scale (see
} 
find out producer willingness to invest in high-quality/labeled products may suitably complete the analysis.

\section{References}

Andersen, Steffen, Glenn W. Harrison, Morten I. Lau, and E. Elisabet Rutström. 2006. “Elicitation Using Multiple Price List Formats.” Experimental Economics, 9(4): 383-405.

Arnot, Chris, Peter C. Boxall, and Sean B. Cash. 2006. "Do Ethical Consumers Care About Price? A Revealed Preference Analysis of Fair Trade Coffee Purchases.” Canadian Journal of Agricultural Economics, 54(4): 555-65.

Bernard, John C., and Daria J. Bernard. 2009. "What Is It About Organic Milk? An Experimental Analysis.” American Journal of Agricultural Economics, 91(3): 826-36.

Blend, Jeffrey R., and Eileen O. van Ravenswaay. 1999. "Measuring Consumer Demand for Ecolabeled Apples.” American Journal of Agricultural Economics, 81(5): 1072-77.

Bougherara, Douadia, and Pierre Combris. 2009. "Eco-labelled Food Products: What are Consumers Paying for?” European Review of Agricultural Economics, 36(3): 321-41.

Fairtrade Labelling Organizations International. 2009. "Fairtrade Leading the Way - Annual Report 2008-09.” Bonn.

Food and Agriculture Organization. 2009. Fisheries Statistical Collections - Global Production. Rome.

Foster, William, and Richard E. Just. 1989. "Measuring Welfare Effects of Product Contamination with Consumer Uncertainty." Journal of Environmental Economics and Management, 17(3): 266-83. 
Fox, John A., Dermot J. Hayes, and Jason F. Shogren. 2002. “Consumer Preferences for Food Irradiation: How Favorable and Unfavorable Descriptions Affect Preferences for Irradiated Pork in Experimental Auctions.” Journal of Risk and Uncertainty, 24(1): 7595.

FranceAgriMer. 2008. "Bilan Annuel 2008 - Consommation des Produits de la Pêche et de l'Aquaculture." Direction Marchés, Etudes et Prospective.

Greenpeace Canada. 2010. Tropical Shrimps and Prawns. Greenpeace Canada Redlist. http://www.greenpeace.org/canada/en/campaigns/oceans/what-we-do/sustainableseafood-markets/redlist/shrimps-prawns (accessed March 25, 2010).

Hayes, Dermot J., Jason F. Shogren, Seung Youll Shin, and James B. Kliebenstein. 1995. "Valuing Food Safety in Experimental Auction Markets." American Journal of Agricultural Economics, 77(1): 40-53.

Hervieu, Sébastien. 2009. “A Madagascar, la Seule Crevette d'Elevage Bio du Monde.” Le Monde, April $1^{\text {st }}, 4$.

Huffman, Wallace E., Matthew C. Rousu, Jason F. Shogren, and Abebayehu Tegene. 2003. "The Public Good Value of Information from Agribusinesses on Genetically Modified Foods.” American Journal of Agricultural Economics, 85(5): 1309-15.

Huffman, Wallace E, Matthew C. Rousu, Jason F. Shogren, and Abebayehu Tegene. 2007. “The Effects of Prior Beliefs and Learning on Consumers' Acceptance of Genetically Modified Foods.” Journal of Economic Behavior \& Organization, 63(1): 193-206.

Loureiro, Maria L., Jill J. McCluskey, and Ron C. Mittelhammer. 2001. "Assessing Consumer Preferences for Organic, Eco-labeled and Regular Apples." Journal of Agricultural and Resource Economics, 26(2): 404-16.

Loureiro, Maria L., and Justus Lotade. 2005. "Do Fair Trade and Eco-labels in Coffee Wake up the Consumer Conscience?" Ecological Economics, 53(1): 129-38. 
Lusk, Jayson L., Lisa O. House, Carlotta Valli, Sara R. Jaeger, Melissa Moore, Bert Morrow, and W. Bruce Traill. 2005. "Consumer Welfare Effects of Introducing and Labeling Genetically Modified Food.” Economics Letters, 88(3): 382-88.

Lusk, Jayson L., and Stéphan Marette. Forthcoming. "Welfare Effects of Food Labels and Bans with Alternative Willingness to Pay Measures." Applied Economic Perspectives and Policy.

Marette, Stéphan, Jutta Roosen, Andrea Bieberstein, Sandrine Blanchemanche, and Frederic Vandermoere. 2009. "Impact of Environmental, Societal and Health Information on Consumers' Choices for Nanofood." Journal of Agricultural \& Food Industrial Organization 7(2): Article 11.

Marette, Stéphan, Jutta Roosen, Sandrine Blanchemanche, and Philippe Verger. 2008. "The Choice of Fish Species: An Experiment Measuring the Impact of Risk and Benefit Information.” Journal of Agricultural and Resource Economics, 33(1): 1-18.

Nimon, Wesley, and John Beghin. 1999. “Are Eco-Labels Valuable? Evidence from the Apparel Industry.” American Journal of Agricultural Economics, 81(4): 801-11.

Rousu, Matthew C., Wallace E. Huffman, Jason F. Shogren, and Abebayehu Tegene. 2004. "Estimating the Public Value of Conflicting Information: The Case of Genetically Modified Foods." Land Economics, 80(1): 125-35.

Rousu, Matthew C., Wallace E. Huffman, Jason F. Shogren, and Abebayehu Tegene. 2007. "Effects and Value of Verifiable Information in a Controversial Market: Evidence from Lab Auctions of Genetically Modified Food.” Economic Inquiry, 45(3): 409-32.

Rousu, Matthew C., and Jayson L. Lusk. 2009. "Valuing Information on GM Foods in a WTA Market: What Information is Most Valuable?" AgBioForum, 12(2): 226-31.

Teisl, Mario F., Nancy E. Bockstael, and Alan Levy. 2001. "Measuring the Welfare Effects of Nutrition Information.” American Journal of Agricultural Economics, 83(1): 133-49. 
Wansink, Brian, Steven T. Sonka, and Clare M. Hasler. 2004. "Front-label Health Claims: When Less is More.” Food Policy, 29(6): 659-67.

Wessells, Cathy R., Robert J. Johnston, and Holger Donath. 1999. “Assessing Consumer Preferences for Ecolabeled Seafood: The Influence of Species, Certifier, and Household Attributes.” American Journal of Agricultural Economics, 81(5): 1084-89.

Willer, Helga, and Lukas Klicher. 2009. "The World of Organic Agriculture - Statistics and Emerging Trends 2009.” IFOAM Bonn, FiBL, Frick, and ITC, Geneva. 
Table 1. Socio-economic characteristics of participants within each group

\begin{tabular}{|c|c|c|c|c|c|c|c|c|c|}
\hline \multirow[t]{2}{*}{ Description } & \multicolumn{2}{|c|}{ Group IA } & \multicolumn{2}{|c|}{ Group IB } & \multicolumn{2}{|c|}{ Group IIA } & \multicolumn{2}{|c|}{ Group IIB } & \multirow{2}{*}{$\begin{array}{l}\text { Chi2 test } \\
P \text { Value }\end{array}$} \\
\hline & $\mathrm{Nb}$. & $\%$ & $\mathrm{Nb}$. & $\%$ & $\mathrm{Nb}$. & $\%$ & $\mathrm{Nb}$. & $\%$ & \\
\hline \multicolumn{10}{|l|}{ Gender } \\
\hline Male & 27 & 64.3 & 15 & 38.5 & 19 & 48.7 & 12 & 30.0 & \multirow{2}{*}{0.013} \\
\hline Female & 15 & 35.7 & 24 & 61.5 & 20 & 51.3 & 28 & 70.0 & \\
\hline \multicolumn{10}{|l|}{ Age } \\
\hline$\leq 30$ & 9 & 21.4 & 9 & 23.1 & 5 & 12.8 & 9 & 22.5 & \multirow{3}{*}{0.940} \\
\hline $31-59$ & 17 & 40.5 & 16 & 41.0 & 18 & 46.2 & 17 & 42.5 & \\
\hline$\geq 60$ & 16 & 38.1 & 14 & 35.9 & 16 & 41.0 & 14 & 35.0 & \\
\hline \multicolumn{10}{|l|}{ Education } \\
\hline No baccalaureate (BAC) & 4 & 9.5 & 5 & 13.9 & 4 & 10.3 & 7 & 17.5 & \multirow{3}{*}{0.252} \\
\hline 2 years after $\mathrm{BAC}$ & 7 & 16.7 & 13 & 36.1 & 7 & 17.9 & 11 & 27.5 & \\
\hline More than 2 years after BAC & 31 & 73.8 & 18 & 50.0 & 28 & 71.8 & 22 & 55.0 & \\
\hline \multicolumn{10}{|c|}{ Monthly net income of the household (€) } \\
\hline$\leq 1500$ & 8 & 19.5 & 10 & 27.0 & 10 & 25.6 & 7 & 18.9 & \multirow{4}{*}{0.939} \\
\hline $1501-3000$ & 11 & 26.8 & 14 & 37.8 & 11 & 28.2 & 13 & 35.1 & \\
\hline $3001-6000$ & 16 & 39.0 & 10 & 27.0 & 13 & 33.3 & 13 & 35.1 & \\
\hline$>6000$ & 6 & 14.6 & 3 & 8.1 & 5 & 12.8 & 4 & 10.8 & \\
\hline \multicolumn{10}{|l|}{ Children } \\
\hline No & 31 & 73.8 & 27 & 69.2 & 24 & 61.5 & 28 & 70.0 & \multirow{2}{*}{0.687} \\
\hline Yes & 11 & 26.2 & 12 & 30.8 & 15 & 38.5 & 12 & 30.0 & \\
\hline \multicolumn{10}{|l|}{ Adults } \\
\hline One & 13 & 31.0 & 18 & 51.4 & 18 & 46.2 & 17 & 42.5 & \multirow{2}{*}{0.302} \\
\hline Two and more & 29 & 69.0 & 17 & 48.6 & 21 & 53.8 & 23 & 57.5 & \\
\hline \multicolumn{10}{|c|}{ Informed about the shrimps' problems } \\
\hline No & 17 & 40.5 & 15 & 38.5 & 19 & 50.0 & 16 & 40.0 & \multirow{2}{*}{0.729} \\
\hline Yes & 25 & 59.5 & 24 & 61.5 & 19 & 50.0 & 24 & 60.0 & \\
\hline
\end{tabular}

Note: For each characteristic, missing observations and answers 'don't know' are dropped from the sample. Baccalaureate is the French high school diploma. 
Table 2. Experimental design

\begin{tabular}{lcc}
\hline \multirow{2}{\text{Typeof}}{$\begin{array}{c}\text { Information Order } \\
\text { Information }\end{array}$} & $\begin{array}{c}\text { Working Conditions (choice \#3) } \\
\text { Environment (choice \#4) }\end{array}$ & $\begin{array}{c}\text { Environment (choice \#3) } \\
\text { Working Conditions (choice \#4) }\end{array}$ \\
\hline Positive & Group IA & Group IB \\
& (42 participants) & (39 participants) \\
\hline Negative & Group IIA & Group IIB \\
& (39 participants) & (40 participants) \\
\hline
\end{tabular}


Table 3. Participants' perceptions of the environment, workers' rights in developing countries, and food safety (increasing scale ranging from 1 to 10 )

\begin{tabular}{|c|c|c|c|c|c|c|c|c|}
\hline \multirow[t]{2}{*}{ Description } & \multicolumn{2}{|c|}{ Group IA } & \multicolumn{2}{|c|}{ Group IB } & \multicolumn{2}{|c|}{ Group IIA } & \multicolumn{2}{|c|}{ Group IIB } \\
\hline & mean & s.d. & mean & s.d & mean & s.d. & mean & s.d. \\
\hline $\begin{array}{l}\text { Informed about food } \\
\text { products safety }\end{array}$ & 5.05 & $(1.80)$ & 5.42 & $(2.19)$ & 5.28 & $(1.75)$ & 5.08 & $(1.93)$ \\
\hline $\begin{array}{l}\text { Informed about } \\
\text { environmental problems }\end{array}$ & 5.81 & $(1.57)$ & 5.67 & $(2.00)$ & 6.56 & $(1.98)$ & 5.82 & $(2.00)$ \\
\hline $\begin{array}{l}\text { Importance attached to the } \\
\text { protection of the } \\
\text { environment }\end{array}$ & 7.64 & $(1.88)$ & 7.59 & $(1.94)$ & 7.82 & $(1.78)$ & 7.46 & $(1.83)$ \\
\hline $\begin{array}{l}\text { Importance attached to the } \\
\text { protection of workers' rights } \\
\text { in developing countries }\end{array}$ & 8.24 & $(1.62)$ & 8.61 & $(1.76)$ & 8.59 & $(1.85)$ & 8.83 & $(1.66)$ \\
\hline Trust in organic labels & 5.68 & $(2.04)$ & 5.35 & $(1.77)$ & 4.74 & $(1.69)$ & 4.85 & $(2.17)$ \\
\hline Trust in fair trade labels & 5.63 & $(2.01)$ & 5.34 & $(2.00)$ & 5.28 & $(1.97)$ & 5.13 & $(2.28)$ \\
\hline
\end{tabular}

Note: s.d.: standard deviation. For each characteristic, missing observations and answers 'don't know' are dropped from the sample. 
Table 4. Influence of information and individual characteristics on WTP

\begin{tabular}{|c|c|c|c|c|c|c|c|}
\hline Model & (1) & (2) & (3) & (4) & (5) & (6) & (7) \\
\hline Dep. Variable & WTP & WTP & WTP & WTP & WTP & WTP & WTP \\
\hline Specification & OLS & OLS & OLS & OLS & OLS & OLS & Tobit \\
\hline Positive info $(0 / 1)$ & $\begin{array}{l}0.71 * * * \\
(0.11)\end{array}$ & $\begin{array}{l}0.73 * * * \\
(0.11)\end{array}$ & $\begin{array}{c}0.72 * * * \\
(0.11)\end{array}$ & $\begin{array}{l}0.75 * * * \\
(0.11)\end{array}$ & $\begin{array}{l}0.75 * * * \\
(0.12)\end{array}$ & & \\
\hline Negative info $(0 / 1)$ & $\begin{array}{c}-0.81 * * * \\
(0.10)\end{array}$ & $\begin{array}{c}-0.81 * * * \\
(0.10)\end{array}$ & $\begin{array}{c}-0.81 * * * \\
(0.10)\end{array}$ & $\begin{array}{c}-0.81 * * * \\
(0.10)\end{array}$ & $\begin{array}{c}-0.73 * * * \\
(0.13)\end{array}$ & & \\
\hline Positive info $\mathrm{x}$ social info $(0 / 1)$ & & & & & & $\begin{array}{c}0.64 * * * \\
(0.16)\end{array}$ & $\begin{array}{c}0.91 * * * \\
(0.25)\end{array}$ \\
\hline Positive info $\mathrm{x}$ environ. info $(0 / 1)$ & & & & & & $\begin{array}{c}0.86 * * * \\
(0.14)\end{array}$ & $\begin{array}{l}1.20 * * * \\
(0.25)\end{array}$ \\
\hline Negative info $\mathrm{x}$ social info $(0 / 1)$ & & & & & & $\begin{array}{c}-0.79 * * * \\
(0.17) \\
\end{array}$ & $\begin{array}{c}-1.34 * * * \\
(0.26) \\
\end{array}$ \\
\hline Negative info $\mathrm{x}$ environ.info $(0 / 1)$ & & & & & & $\begin{array}{c}-0.68 * * * \\
(0.17)\end{array}$ & $\begin{array}{c}-1.13 * * * \\
(0.26)\end{array}$ \\
\hline Negative info $x$ safety info $(0 / 1)$ & & & & & & $\begin{array}{c}-0.88^{* * *} \\
(0.13) \\
\end{array}$ & $\begin{array}{c}-1.50 * * * \\
(0.21) \\
\end{array}$ \\
\hline Female $(0 / 1)$ & & $\begin{array}{l}-0.03 \\
(0.10)\end{array}$ & & $\begin{array}{c}0.02 \\
(0.10) \\
\end{array}$ & $\begin{array}{l}-0.01 \\
(0.11)\end{array}$ & $\begin{array}{c}0.02 \\
(0.10) \\
\end{array}$ & $\begin{array}{l}-0.03 \\
(0.16)\end{array}$ \\
\hline Age & & $\begin{array}{c}-0.006 * * \\
(0.003) \\
\end{array}$ & & $\begin{array}{c}-0.007 * * \\
(0.003) \\
\end{array}$ & $\begin{array}{c}-0.009 * * * \\
(0.003)\end{array}$ & $\begin{array}{c}-0.007^{* *} \\
(0.003) \\
\end{array}$ & $\begin{array}{l}-0.01 * * \\
(0.004) \\
\end{array}$ \\
\hline Children $(0 / 1)$ & & $\begin{array}{c}0.20 * * \\
(0.10)\end{array}$ & & $\begin{array}{l}0.22 * * \\
(0.10)\end{array}$ & $\begin{array}{l}0.22 * * \\
(0.11) \\
\end{array}$ & $\begin{array}{c}0.22 * * \\
(0.10)\end{array}$ & $\begin{array}{c}0.33^{* *} \\
(0.16)\end{array}$ \\
\hline Educ.: no $\mathrm{BAC}^{\diamond}(0 / 1)$ & & - & & - & - & - & - \\
\hline Educ.: $\left[\mathrm{BAC}^{\diamond}-\mathrm{BAC}^{\diamond}+2\right](0 / 1)$ & & $\begin{array}{l}0.36^{* *} \\
(0.15) \\
\end{array}$ & & $\begin{array}{l}0.34 * * \\
(0.16) \\
\end{array}$ & $\begin{array}{c}0.28 \\
(0.18) \\
\end{array}$ & $\begin{array}{l}0.35^{* *} \\
(0.16) \\
\end{array}$ & $\begin{array}{l}0.57 * * \\
(0.27) \\
\end{array}$ \\
\hline Educ.: $\mathrm{BAC}^{\vartheta}+5$ and more $(0 / 1)$ & & $\begin{array}{l}0.30 * * \\
(0.14)\end{array}$ & & $\begin{array}{l}0.28 * \\
(0.15) \\
\end{array}$ & $\begin{array}{c}0.17 \\
(0.17) \\
\end{array}$ & $\begin{array}{l}0.28^{*} \\
(0.15)\end{array}$ & $\begin{array}{l}0.46^{*} \\
(0.25)\end{array}$ \\
\hline $\begin{array}{l}\text { Importance attached to the } \\
\text { protection of environment }(0 / 1)\end{array}$ & & & $\begin{array}{c}-0.29^{* *} \\
(0.15) \\
\end{array}$ & $\begin{array}{l}-0.26^{*} \\
(0.16)\end{array}$ & $\begin{array}{c}-0.33^{* *} \\
(0.16)\end{array}$ & $\begin{array}{l}-0.26^{*} \\
(0.16)\end{array}$ & $\begin{array}{l}-0.48^{*} \\
(0.25)\end{array}$ \\
\hline $\begin{array}{l}\text { Importance attached to the } \\
\text { protection of workers' rights }(0 / 1)\end{array}$ & & & $\begin{array}{c}0.04 \\
(0.17) \\
\end{array}$ & $\begin{array}{l}-0.14 \\
(0.18) \\
\end{array}$ & $\begin{array}{l}-0.06 \\
(0.19) \\
\end{array}$ & $\begin{array}{l}-0.14 \\
(0.18)\end{array}$ & $\begin{array}{l}-0.31 \\
(0.31)\end{array}$ \\
\hline Constant & $\begin{array}{c}2.03 * * * \\
(0.07) \\
\end{array}$ & $\begin{array}{c}1.99 * * * \\
(0.22) \\
\end{array}$ & & $\begin{array}{c}2.37 * * * \\
(0.27) \\
\end{array}$ & $\begin{array}{c}2.56^{* * * *} \\
(0.29) \\
\end{array}$ & $\begin{array}{c}2.38 * * * \\
(0.27) \\
\end{array}$ & $\begin{array}{c}2.61 * * * \\
(0.47) \\
\end{array}$ \\
\hline $\begin{array}{l}\text { Observations } \\
\mathrm{R}^{2}\end{array}$ & $\begin{array}{c}800 \\
0.169 \\
\end{array}$ & $\begin{array}{c}785 \\
0.193 \\
\end{array}$ & $\begin{array}{c}790 \\
0.173 \\
\end{array}$ & $\begin{array}{c}775 \\
0.198\end{array}$ & $\begin{array}{c}620 \\
0.185 \\
\end{array}$ & $\begin{array}{c}775 \\
0.200 \\
\end{array}$ & $\begin{array}{c}775 \\
0.065\end{array}$ \\
\hline
\end{tabular}

Note: ${ }^{\curvearrowright}:$ In the French system, the high school diploma is called 'baccalaureate' (BAC). ${ }^{* * *}$ : significant at $1 \%$; **: significant at 5\%; *: significant at 10\%. Robust estimations. Standard errors in parentheses.

F-test for parameters equality: column (2): F-test on education variables $=0.551$; Column (6): F-test on positive info. $\mathrm{x}$ social info. and positive info. $\mathrm{x}$ environmental info. $=0.256 ;$ F-test on negative info $\mathrm{x}$ social info, negative info. $\mathrm{x}$ environmental info. and negative info. $\mathrm{x}$ safety info. $=0.591$; Column (7): F-test on positive info. $\mathrm{x}$ social info. and positive info. $\mathrm{x}$ environmental info. $=0.364$; F-test on negative info $\mathrm{x}$ social info, negative info. $\mathrm{x}$ environmental info. and negative info. $\mathrm{x}$ safety info. $=0.445$. 
Table 5. Value of information

\begin{tabular}{|c|c|c|c|c|}
\hline Groups & $\begin{array}{c}\text { IA } \\
\text { Positive } \\
\& \text { social } \\
\text { information }\end{array}$ & $\begin{array}{c}\text { IB } \\
\text { Positive \& } \\
\text { environment } \\
\text { information }\end{array}$ & $\begin{array}{c}\text { IIA } \\
\text { Negative } \\
\& \text { social } \\
\text { information }\end{array}$ & $\begin{array}{c}\text { IIB } \\
\text { Negative \& } \\
\text { environment } \\
\text { information }\end{array}$ \\
\hline \multicolumn{5}{|l|}{ Participants receiving positive information } \\
\hline $\begin{array}{l}\text { Participants who switch to labeled varieties after } \\
\text { positive information }(\%)\end{array}$ & $19 \%$ & $20.5 \%$ & & \\
\hline Value of information $\Delta C S_{\text {Label }}^{S_{P}}$ (switchers) & $€ 0.76$ & $€ 0.53$ & & \\
\hline Value of information $\Delta C S_{\text {Label }}^{N_{P}}$ (all participants) & $€ 0.14$ & $€ 0.11$ & & \\
\hline \multicolumn{5}{|l|}{ Participants receiving negative information } \\
\hline $\begin{array}{l}\text { Participants who switch to avoid purchasing } \\
\text { regular variety after negative information }(\%)\end{array}$ & & & $33.3 \%$ & $30 \%$ \\
\hline Value of information $\Delta C S_{\text {Neg }}^{S_{N}}$ (switchers) & & & $€ 1.05$ & $€ 1.45$ \\
\hline Value of information $\Delta C S_{N e g}^{N_{N}}$ (all participants) & & & $€ 0.35$ & $€ 0.43$ \\
\hline \multicolumn{5}{|l|}{ Combination of groups } \\
\hline \multicolumn{5}{|l|}{$\begin{array}{l}\text { Case 1: Consumers only aware of the positive } \\
\text { information coming from the label }\end{array}$} \\
\hline Average cost of ignorance $E(C O I)$ & & & $€-1.04$ & $€-0.95$ \\
\hline $\begin{array}{l}\text { Participants who switch to labeled varieties after } \\
\text { positive information }(\%)\end{array}$ & $19 \%$ & $20.5 \%$ & & \\
\hline Value of information $\triangle C S D_{\text {Label }}^{S_{P}}$ (switchers) & $€ 1.27$ & $€ 1.12$ & & \\
\hline Value of information $\triangle C S D_{\text {Label }}^{N_{P}}$ (all participants) & $€ 0.24$ & $€ 0.23$ & & \\
\hline \multicolumn{5}{|l|}{$\begin{array}{l}\text { Case 2: Consumers aware of positive and } \\
\text { negative information }\end{array}$} \\
\hline Average cost of ignorance $E(C O I)$ & & & $€-1.04$ & $€-0.95$ \\
\hline $\begin{array}{l}\text { Participants who switch to labeled varieties after } \\
\text { positive information }(\%)\end{array}$ & $45.2 \%$ & $59 \%$ & & \\
\hline Value of information $\triangle C S E_{\text {Label }}^{S_{P}}$ (switchers) & $€ 1.03$ & $€ 0.87$ & & \\
\hline Value of information $\triangle C S E_{\text {Label }}^{N_{P}}$ (all participants) & $€ 0.47$ & $€ 0.51$ & & \\
\hline
\end{tabular}


Table 6. Income increase for producers

\begin{tabular}{ccc}
\hline Type of information revealed by the label & $\begin{array}{c}\text { Positive } \\
\text { \& social } \\
\text { information }\end{array}$ & $\begin{array}{c}\text { Positive \& } \\
\text { environment } \\
\text { information }\end{array}$ \\
\hline Participants who switch to labeled varieties & $19 \%$ & $20.5 \%$ \\
Purchasing the regular variety before the label & $9.5 \%$ & $12.8 \%$ \\
Not purchasing shrimps before the label & $9.5 \%$ & $7.7 \%$ \\
Increase in producers' marginal income & $14 \%$ & $11 \%$ \\
\hline Note: relative variation (\%) compared to the total income for year without any label in parentheses.
\end{tabular}


General Instructions

Entry questionnaire

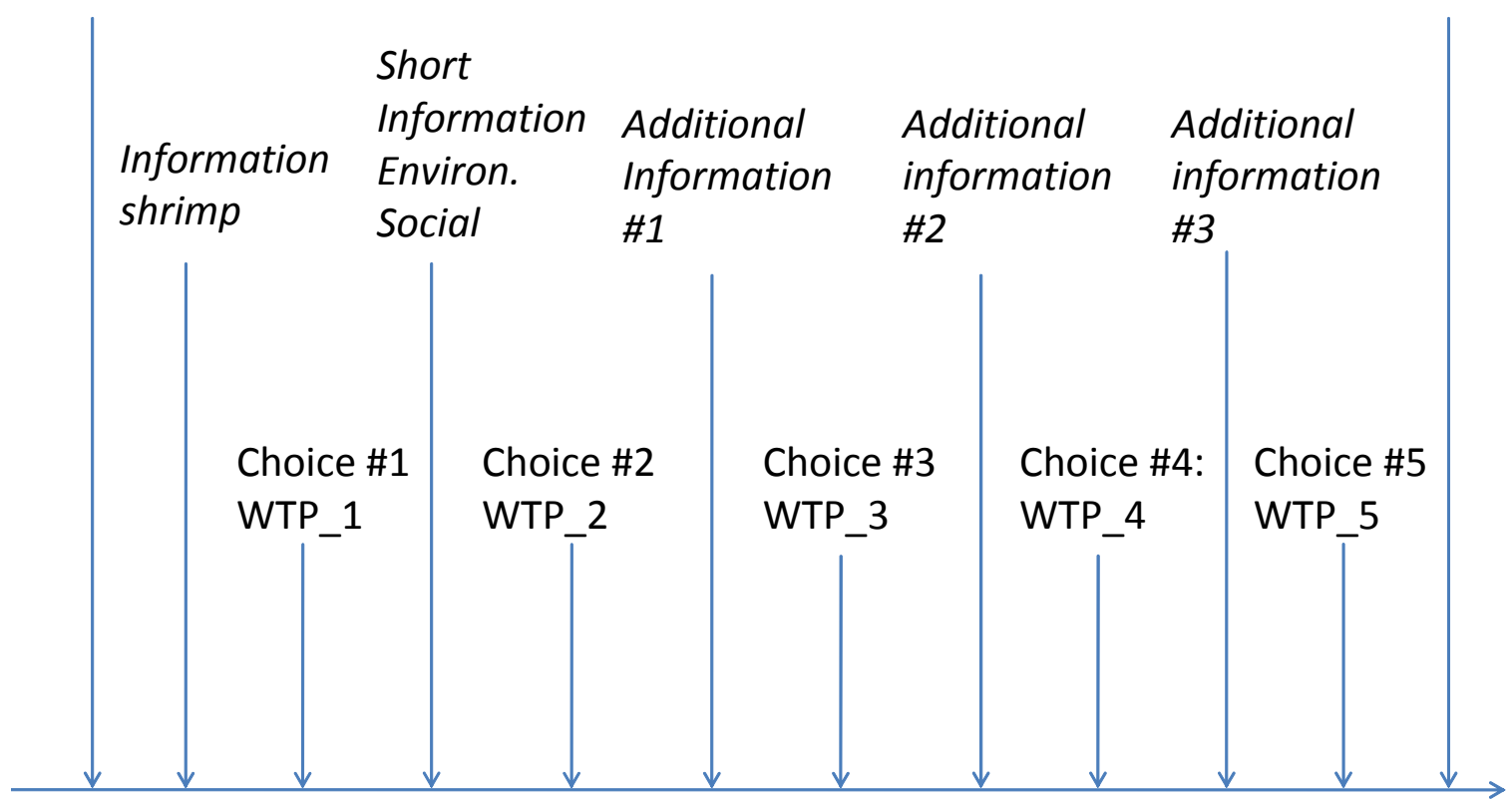

Figure 1: Timeline 
Average WTP for shrimps with labels for GROUP IA

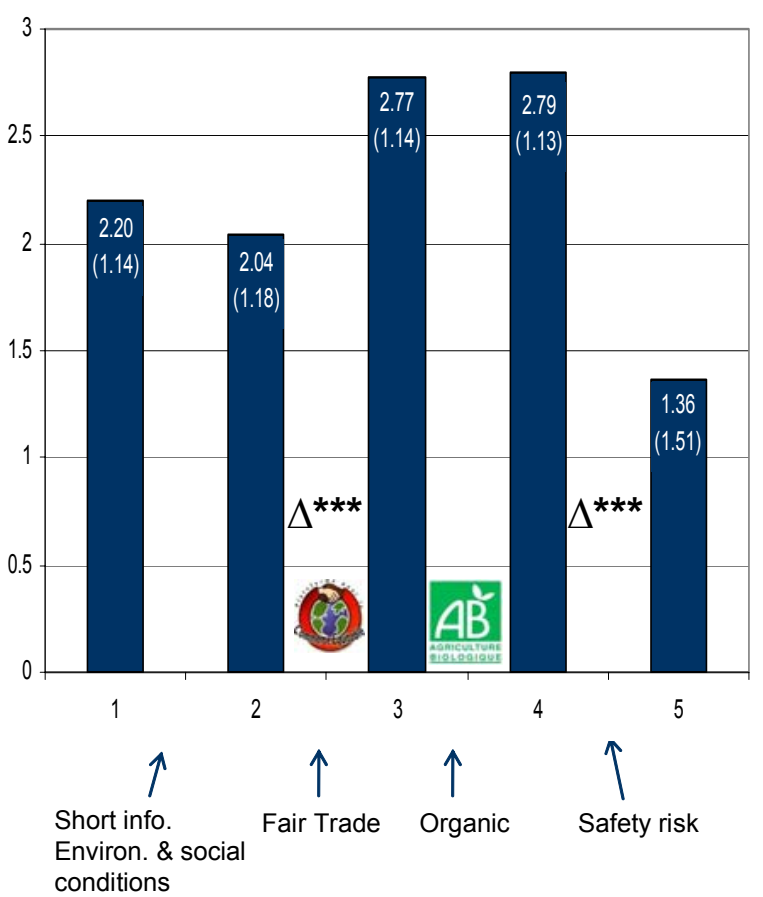

Average WTP for shrimps with labels for GROUP IB

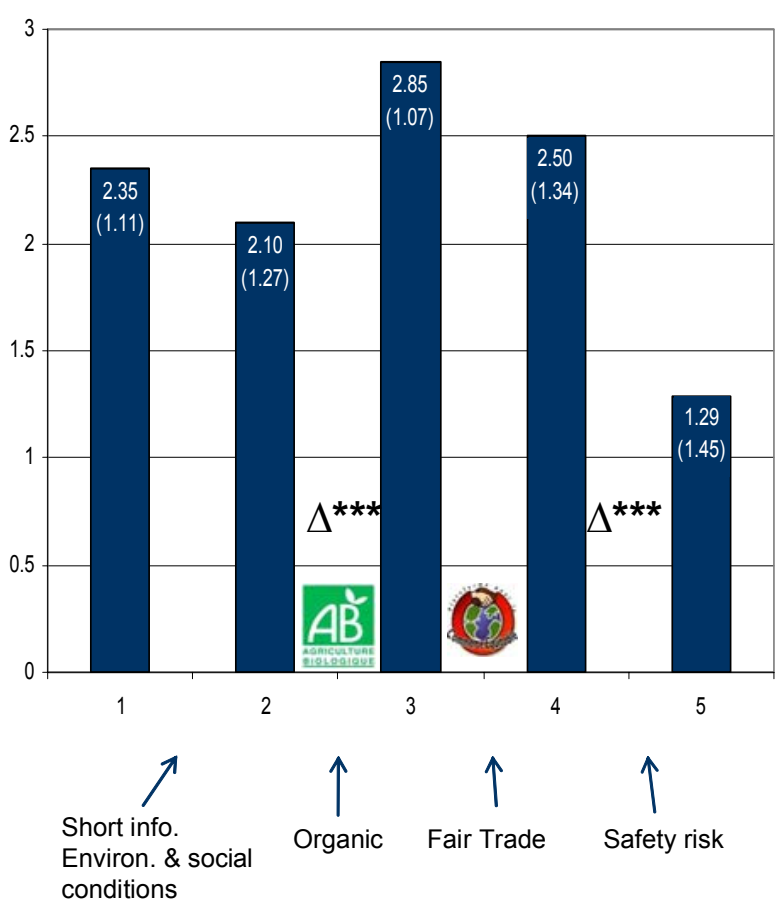

Note: WTP in $€ ; \Delta^{* \star \star}$ denotes significant differences at the $1 \%$ level as tested by the Wilcoxon test for comparing paired samples.

Figure 2. Impact of positive information 
Average WTP for shrimps without labels for GROUP IIA



Average WTP for shrimps without labels for GROUP IIB

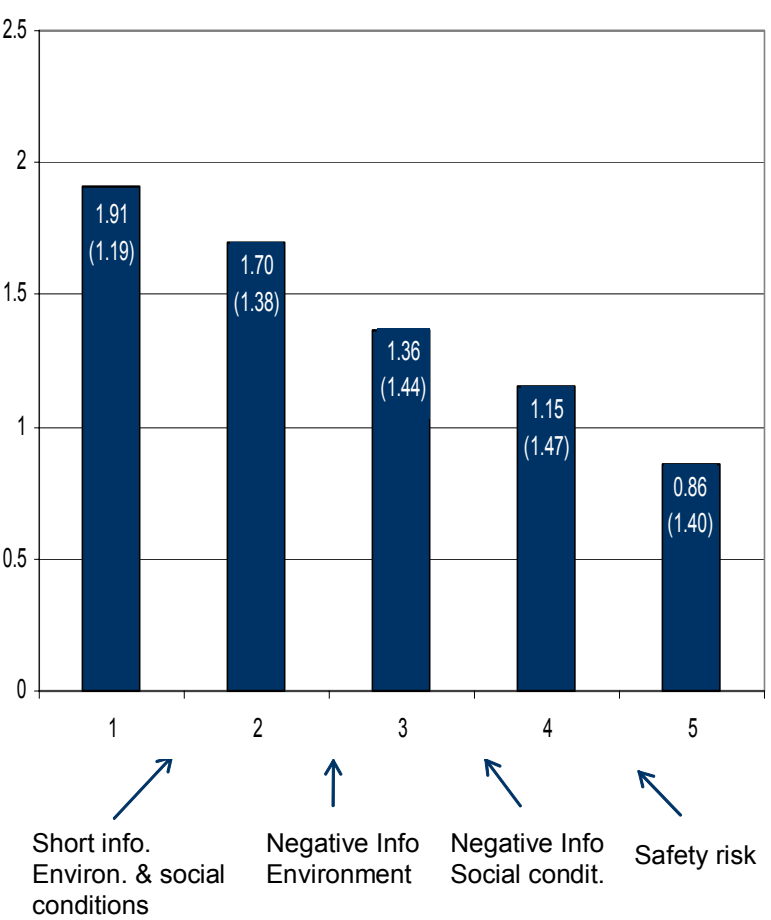

Note: WTP in $€ ; \Delta^{* *}$ denotes significant differences at the $5 \%$ level and $\Delta^{*}$ denotes significant differences at the $10 \%$ level as tested by the Wilcoxon test for comparing paired samples.

Figure 3. Impact of negative information 


\section{Appendix 1: Revealed information}

The precise messages are translated from the original French.

\section{The initial information before choice \#1}

Please read carefully the following information:

"In what follows we will present you information about farmed, midsize, cooked, shelled and refrigerated shrimps. On the market, the average price for $100 \mathrm{~g}$ of shrimps varies between $€ 1.50$ and $€ 4$."

Choice \#1 with the colored picture.

\section{The general information before choice \#2}

On a new and separate sheet

Please read carefully the following information:

"There are serious concerns about bad conditions for the environment and workers in shrimp farms from different countries around the world. Many shrimps consumed in France are imported from these countries."

Choice \#2 with the colored picture.

\section{The different types of information before choices \#3 and \#4}

Positive information for groups IA and IB

On a new and separate paper sheet

Please read carefully the following information:

"Fair Trade Shrimps:

In some countries, shrimp producers develop fair trade production, with decent working hours, decent wages, and controlled handling of chemical products used by workers to treat and to clean the shrimps in order to protect workers' health.

These practices, on average, significantly increase the production costs.

These products are sold with a "fair trade" label in France."

Choice \#3 or \#4 with the colored picture and the fair trade label.

On a new and separate paper sheet

Please read carefully the following information:

"Organic shrimps:

In some countries, shrimp producers develop environmentally friendly production schemes.

Discharges are limited and pollution is controlled. Furthermore, the quality of water and ecosystems around the farms is preserved.

These practices, on average, significantly increase the production costs.

These products are sold with an organic label in France."

Choice \#3 or \#4 with the colored picture and the organic label.

Negative information for groups IIA and IIB

On a new and separate paper sheet

Please read carefully the following information:

"Social concerns:

In some countries, among the biggest shrimp producers and exporters, workers in shrimp farms and factories work 12 or 16 hours per day for a very small salary.

Furthermore, without any protection, workers handle chemical products that are toxic to human health and used to treat and clean the shrimps. 
Given the difficulties and the cost of inspection of imported products, it is likely that a large share of shrimps sold in France was produced in such conditions."

Choice \#3 or \#4 with the colored picture.

On a new and separate paper sheet

Please read carefully the following information:

"Environmental concerns:

Shrimp farms can generate serious environmental problems. In particular, the discharges coming from farms are a source of pollution: deterioration of water quality and of fertility of soils, which were converted into breeding pools.

Given the difficulties and the cost of inspection of imported products, it is likely that the production of a large share of shrimps sold in France generated such pollution."

Choice \#3 or \#4 with the colored picture.

\section{Information before choice \#5}

On a new and separate paper sheet

Please read carefully the following information:

"Health concerns:

Many bacteriological infections affect shrimp breeding pools. The bad production conditions (bad water quality for example) favor the growth of bacteria. To fight against these bacteria, the shrimp producers use antibiotics and other chemical products that are toxic to human health and therefore forbidden in almost all countries.

Given the difficulties and the cost of inspection of imported products, it is likely that some shrimps sold in France were treated with these antibiotics and chemical products toxic to human health." 


\section{Appendix 2: Multiple price list and pictures.}

In the following you will be asked for your willingness to buy each of these products. For each line, check off either yes, no or maybe. Please check off one option for every price.

Your choice:

Farmed, cooked, midsize, shelled and refrigerated shrimps.

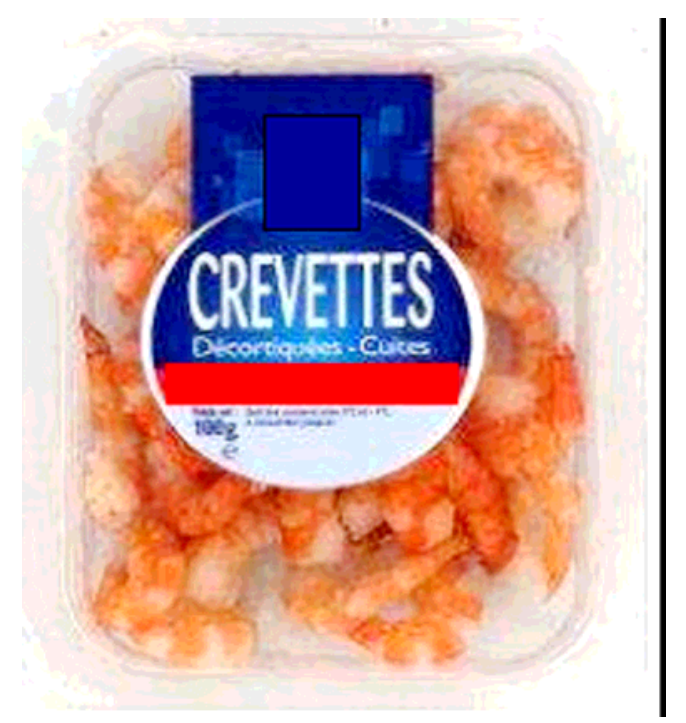

Remind: On the market, the average price for $100 \mathrm{~g}$ of these shrimps varies between $€ 1.50$ and $€ 4$.

Would you be willing to buy $100 \mathrm{~g}$ of shrimps?

0.25 euro

YES NO Maybe

0.50 euro

0.75 euro

1 euro

1.25 euro

1.50 euro

1.75 euro

2 euros

2.25 euros

2.50 euros

2.75 euros

3 euros

3.25 euros

3.50 euros

3.75 euros

4 euros 
For the positive information linked to the fair trade ("commerce équitable"), the picture before the multi price list is as following:
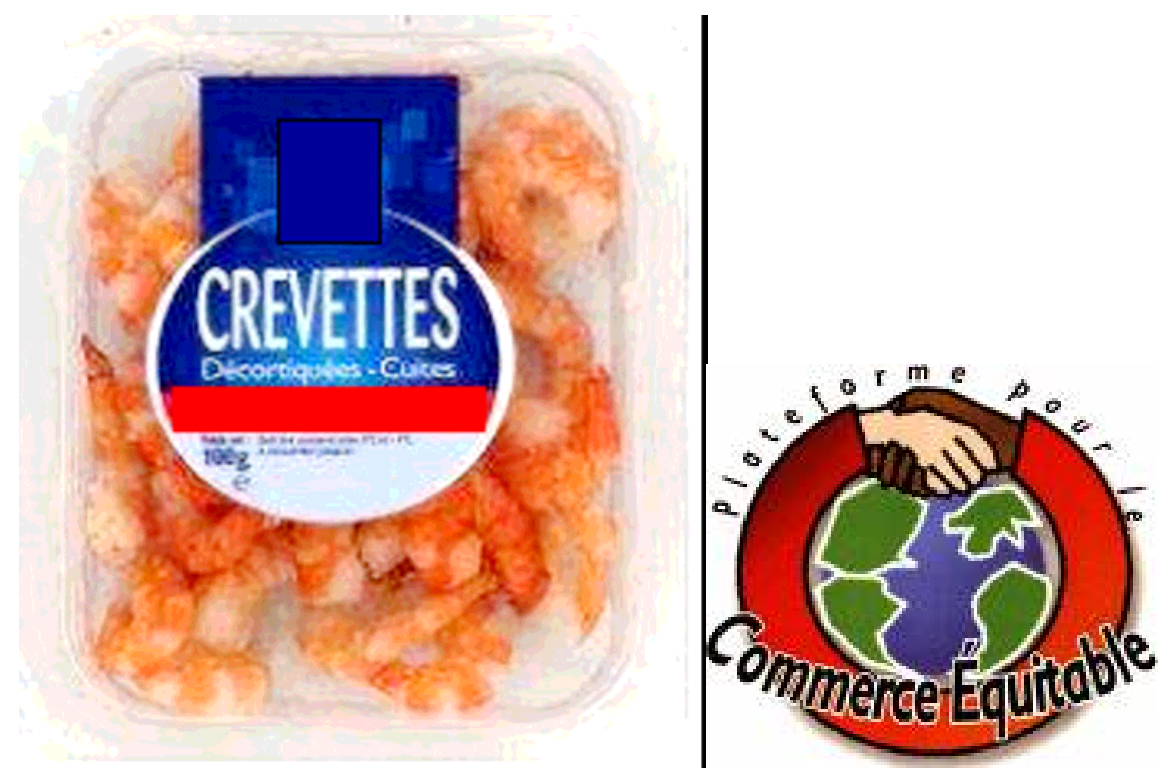

For the positive information linked to the organic label ("agriculture biologique"), the picture before the multi price list is as following:

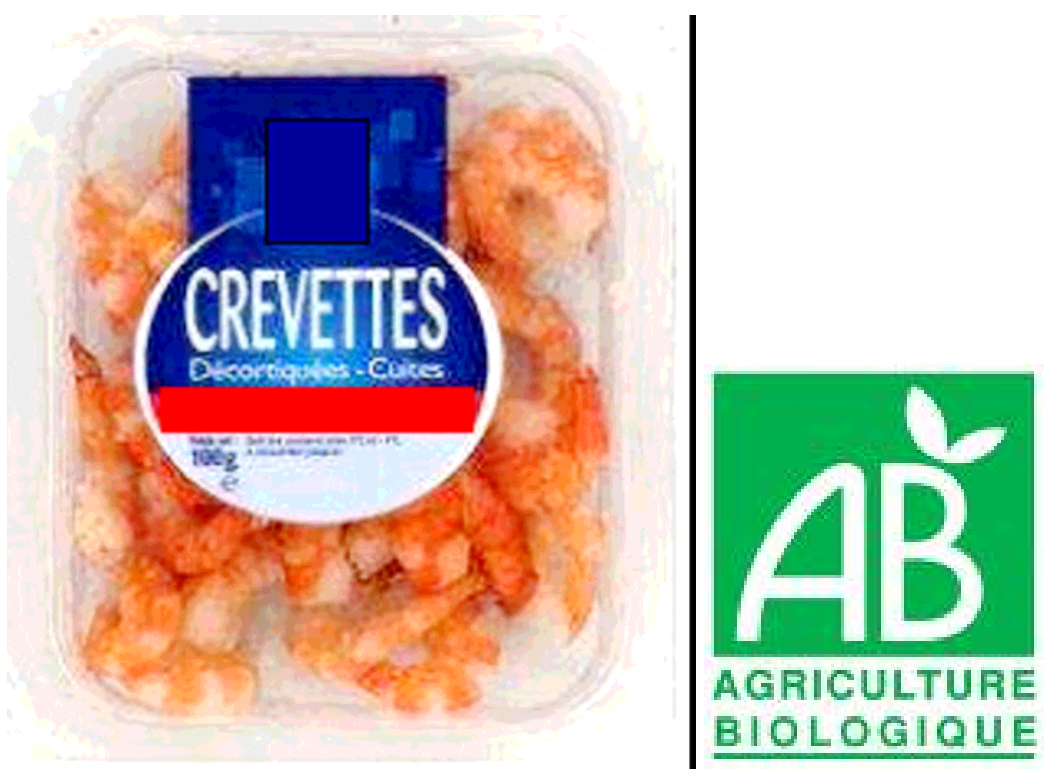

